date, pre-war publication of this firm, which for so long has been indicative of what might once have been obtained, can be replaced by this new list of what is now available. It is obvious from the contents of the catalogue that the scientific apparatus industry of Great Britain has not only completed the transition from war to peace manufacture, but has also expanded its range of products to cover gaps in its production which existed before the War ; every article in this most comprehensive list of scientific apparatus is made either by the firm itself or by some other British manufacturer. The catalogue is an attractive publication, and in its arrangement due attention has evidently been paid to the convenience of the user. The catalogue is divided into thirteen sections, each dealing with the apparatus and instruments required for the teaching and experimental work of a particular subject in university and other educational laboratories. In addition, there are a list of chemicals and reagents and a very full index. One very useful aspect of the catalogue is the full description given of many of the items, together with articles on the methods and theory of use. Messrs. Griffin and Tatlock are to be congratulated on this praiseworthy effort.

\section{Publication of Papers on Physics}

Prof. E. N. DA C. ANDrade, in his presidential address to the Physical Society in 1945 , referred to the "need of a medium for the publication of original papers on physical problems whose main interest was industrial and technical" (Proc. Phys. Soc., 57, 21 ; 1945). To meet this need the Board of the Institute of Physies and the Council of the Physical Society have proposed the introduction of a now journal of applied physics, which, it is hoped, will commence early in 1948. A journal of about $\mathbf{4 0 0}$ pages a year, issued quarterly, is contemplated, devoted to applications of physics, containing papers on original work in technical physics, border-line papers on subjects which are not strictly 'fundamental' physics, reviews of recent advances, discussions, and, probably, editorials, notices of meetings and news items. A Joint Advisory Panel, on which every Group of the Society and all the Groups and local Branches of the Institute will be represented, is to be set up to work out the details. The rate of subscription to the new journal will, at first, be one guinea a year to members of the Society or Institute, and about $30 s$. to nonmembers.

In his address, Prof. Andrade pointed out also that the increased number of papers communicated to the Physical Society for publication would necessitate issuing two volumes a year of the Proceedings instead of the present one. The Council has accordingly announced that, from January 1948, the Proceedings will appear in two volumes a year, each consisting of six parts issued monthly, in order that the period between the communication and publication of papers may be reduced. In spite of the title Proceedings, a change of which was recently proposed but rejected by the members, papers are published in the Society's journal which are not necessarily a part of the proceedings of meetings. It is felt that, as many Continental physical journals ceased publication during the War and have not yet reappeared, Continental physicists may find a medium for the publication of their work in the Society's journal, now that more space and more rapid publication are assured.

\section{Paper for Technical Journals}

Mr. H. WILson, president of the Board of Trade, replying to Mr. Erroll in the House of Commons on October 30, said that steps are being taken to ensure to journals devoted primarily to original research their full requirements of paper, and he hopes to exempt technical periodicals from the reduction which it is necessary to make in the paper available for periodicals generally.

\section{Breeding of the Moustached Warbler in Britain}

Conclusstve evidence produced by R. A. Hinde and A. S. Thom (British Birds, 40, No. 4; April 1947) shows that the first recorded breeding of the moustached warbler (Lusciniola melanopogon) in the British Isles took place in Cambridgeshire in 1946. The evidence was compounded from observations made by a group of distinguished ornithologists, and the dark crown and superciliary stripe, as well as the cocking of the tail, leave no doubt that this Mediterranean bird, the nearest part of whose normal range is the south of France and whose sole previous claim to a place in the British list rested on a single occurrence, must now be added to the list of birds which have been known to breed in Britain.

\section{Swiss Earthquakes during 1945}

THIS annual seismological report of the Swiss observatories has been compiled by Dr. E. Wanner of Zurich. Seismographs are installed at the Swiss Observatories of Zurich, Chur, Neuchâtel, Basel and Brig, and during the year 85 noar earthquakes and 189 strong distant earthquakes were registered. There were ten earth tremors with epicentres in Switzerland which were felt by people during the year. None of these had a greater intensity than $V$ on the RossiForel Scale, so that none reached destructive intensity. The greatest three tremors were (1) May 13 at Freiburg, (2) October 13 at Engadine and (3) November 10 at Wildhorn.

\section{Science in the U.S.S.R.}

A symposium on "Science and the Soviet State" in honour of the thirtieth anniversary of the U.S.S.R. is being organised by the Science Section of the Society for Cultural Relations with the U.S.S.R., 14 Kensington Square, London, W.8. The chairman of the meeting, which will be held at the Caxton Hall, London, S.W.1, on November 12, at 6.30 p.m., will be Sir Robert Watson-Watt, and speakers will include Prof. J. D. Bernal on "The Scientist as Citizen", Prof. V. Gordon Childe on "Archæology and the State", and Mr. Andrew Rothstein on "Science and Economic Planning". Tickets for the meeting $(2 s .6 d$. each) can be obtained from the Society for Cultural Relations.

\section{Medical Sub-section of the Library Association}

THE inaugural meeting of a new Medical Subsection of the Library Association was held at Chaucer House on October 4. The following committee was appointed to manage the affairs of the group : C. C. Barnard, London School of Hygiene and Tropical Medicine (chairman); Miss F. Wigmore, Medical Research Council; W. A. Lee, Liverpool Medical Institution; W. R. Le Fanu, Royal College of Surgeons of England; T. J. Shields, British Medical Association; G. Wilson, Medical Library, University of Manchester; and W. J. Bishop, Wellcome Historical Medical Museum, 28 Portman Square, London, W.1 (hon, secretary). 